\title{
Criticality Analysis of Medical Equipment: A Case Study at King Hussein Cancer Center (KHCC) Amman-Jordan
}

\author{
https://doi.org/10.3991/ijoe.v15i15.11613
}

\author{
Abdul Kareem Abdul Jawwad ( $\left.{ }^{\square}\right)$ \\ King Abdul-Aziz University, Rabigh, Saudi Arabia \\ The University of Jordon, Amman, Jordon \\ akjawwad@ju.edu.jo \\ Muhammad Saleem \\ King Abdul-Aziz University, Rabigh, Saudi Arabia
}

\begin{abstract}
Criticality analysis was performed on a representative sample of medical equipment at King Hussein Cancer Center (KHCC), Amman-Jordan, in order to assess and improve the effectiveness of current maintenance management policy. A sample of twenty-one medical devices was selected for this study. Past failure and maintenance data, in addition to relevant financial information were collected for these devices and compiled into criticality ranks. In order to take account of the special nature of this equipment medical criticality (in terms of risk score) values were also calculated based on relevant tables of the American Society for Healthcare Engineering (ASHE). Overall criticality ranking of medical equipment was then determined based on equipment cost, ASHE risk score, reliability and maintenance cost. The present results have revealed major flaws within the purchase and maintenance policies at KHCC. For example, some extremely expensive devices with extremely high-cost maintenance contracts were revealed to exhibit low reliability values and suffer from repeated failures. These were within patient-sensitive cancer treatment devices. The results also have shown that under "less than optimum" maintenance practice, the ASHE risk score may be a misleading measure of equipment criticality. This was shown by comparing the obtained overall equipment criticality to their ASHE risk score where high level of discrepancy was present between the two measures.
\end{abstract}

Keywords - Criticality analysis, Medical Equipment, Reliability, Maintenance, Biomedical engineering, KHCC.

\section{$1 \quad$ Introduction and Literature Review}

Proper maintenance management of medical equipment is of prime importance to the health sector as otherwise this would result in poor treatment, longer waiting times and patients suffering as well as draining, the normally limited, financial resources of most public medical institutions. Medical devices usually consist of large number of components interacting with each other making complex repairable systems. In case 
of a failure, the repairable system can be brought to adequate performance without replacing the whole system. Such systems usually go through periodic or non-periodic planned inspections during their life cycle. In practice, preventive maintenance (PM) is the most widely applied maintenance scheme for repairable systems [1]. This is normally achieved through regular planned checkups and maintenance; i.e., periodic PM.

In order to assure the system safety and performance of medical devices, PM plays a very important role in clinical engineering. Potential failures can be detected through planned periodic inspections and appropriate mitigation measures are taken to fix these failures. In case of having no failure, performing preventive maintenance can avoid or reduce future failures [2].

Preventive maintenance intervals are an important discussion topic among clinical engineering professionals at various levels. Unnecessary and excessive PM could be very expensive. Accreditation organizations and regulating authorities, in many countries, require that PM intervals should be in accordance with equipment manufacturer's recommendations [3]. However, it does not seem a practical approach to debate these intervals with equipment manufacturers because they might not share the information about any documented data with the clients. In consequence, maintenance outcomes judgment and the periodic replacement of parts based on PM would not be possible [4].

The experience from different other industries shows that traditional PM is often unnecessary. However, clinical and biomedical engineering professionals are still focusing on to process measures instead of maintenance outcome analysis [5].

Hospitals and other medical institutions normally adopt a Medical Equipment Management Program (MEMP) in order to ensure the safety and reliability of critical devices. MEMP would usually engulf such activities as inspection, PM and testing. These activities should, however, be reviewed continuously in order to meet the increasing demands of healthcare organizations as well as to align with current technological advancements [6].

Over the last two decades, the reliability prediction of medical systems have been considered by many researchers at the design and development stage, however, less literature deals with the reliability prediction for medical devices while in use [7].

A brief set of guidelines for maintenance management of medical devices as well as methods, such as Reliability Centered Maintenance (RCM), which have been used for a long time in other industries, are provided in reference [8]. RCM is a highly developed set of procedures aimed at the determination of maintenance requirements for the different assets in any firm. This would normally involve a comprehensive and strict decision process. When there is various distinct equipment with non-obvious failure consequences, asset criticality evaluation becomes a cornerstone and is the first step towards applying the RCM [9] and [10].

Although criticality is considered as a measure of equipment importance within an organization, it is also of an indication about the level of attention that should be allocated to an asset. From a maintenance and reliability viewpoint, one dimension of asset criticality is defined based on the consequences of this asset experiencing an event of failure or a breakdown. This, in turn, is determined through factors such as 
timing, severity, detectability, probability and costs incurred [11]. In healthcare organizations, risk is also an important measure of criticality for medical equipment. In this context, risk, however, is looked at from a medical point of view which reflects the effect of an equipment failure on the patient's treatment and/or ultimately patient's life. This definition of risk should be distinguished from the generic denotation of risk used in RCM. Medical risk is normally determined by standard procedures based on individual equipment's risk scores [12]. This subject will be given further treatment later in this paper. A concept relevant to this topic is the perspective set by Dekker et al. [13] for equipment criticality; which looks at critical equipment through their function or use and not the equipment itself. On this basis equipment that might be critical under certain circumstances (such as lack of redundancy) may very well become an auxiliary one under different conditions (for example presence of other substitutes). Significant and critical assets should be identified and prioritized. Several techniques have been developed for criticality assessment. Most use some variation of the priority risk number (PRN) which is a product of the probability of failure of an asset, severity of the consequence of the failure, and detectability of the failure.

Fennigkoh and Smith [14] proposed a risk assessment method to group medical devices on the basis of their Equipment Management (EM) numbers. EM is the sum of the numbers assigned to the device's critical function, physical risk and required maintenance.

When EM number is above a critical threshold value (less than or equal to 12), devices are then considered to have critical risk and are therefore included for the inspection and maintenance plans. While the above discussion briefly summarizes the subject of criticality in relation to medical equipment in general, there remains an important facet to be considered in relation to this subject; that is the specific regional/geographical location involved in the study. Preventive maintenance practice, whether periodic or non-periodic, may not be at the same level in developing countries compared to well-developed industrial countries [15].This is mainly due to issues like maintenance budget limitations [16], longer lead times involved in ordering and receiving spare parts and replacements [17], exhaustive administrative and clerical procedures involved due to highly centralized decision making hierarchy structures especially within public hospitals and medical centers [18], the lack of efficient documentation and logging procedures [19] and dominant political situations [20]. The present study was carried out at King Hussein Cancer Center (KHCC) located in Amman-Jordan. Despite the noticeable multi-dimensional advancements that have taken place within different industrial and commercial sectors recently in Jordan, substantial efforts are still needed to attain a world-class maintenance practice within medical institutions [21]. This is due to the above-mentioned factors and also due to the increasingly volatile political situation around Jordan which places additional economic and social pressures on the country. This implies that diligent and tight procedures must be put forward for maintenance budget allocations especially within highly critical medical institutions where highest level of equipment reliability and efficient financial strategies, in dealing with increasing economic pressures, are a prerequisite for a sustainable and acceptable level of patient service.KHCC is a unique medical institution where treatment of different types of cancer is provided 
and where equipment unavailability is considered a high-risk event and may result in life-threatening complications.

In light of the above, the main objective of this study is to perform a criticality study on a representative sample of medical equipment at KHCC in order to establish a robust procedure for criticality ranking of medical equipment and help assess and improve the effectiveness of current maintenance management policies at KHCC. This main objective would be achieved through the following sub-objectives:

- Assess the effectiveness of the present maintenance policy at KHCC by determination of equipment reliabilities

- Construct a systematic technique to measure equipment criticality that incorporates several dimensions including medical, financial and reliability measures.

- Analyze the main causes that would affect equipment criticality.

- Rank a sample set of equipment according to their new criticality values

- Evaluate maintenance strategy for each equipment evaluated and propose some recommendations in regard to their maintenance activities, especially for those "highly critical" equipment

\section{Criticality and Maintenance of Medical Equipment at KHCC}

This section explains the current practice at $\mathrm{KHCC}$ in relation to criticality and maintenance of its medical equipment.

\subsection{Criticality ranking of medical equipment}

Criticality ranking at $\mathrm{KHCC}$ is based solely on risk classification for clinical equipment developed by the American Society for Healthcare Engineering (ASHE).

In this classification, clinical equipment is evaluated based upon the following risk criteria:

Risk Category I: Equipment function (E); this factor includes different areas like therapeutic, diagnostic, analytical and miscellaneous in which equipment are used.

Risk Category II: Clinical application (A); this factor relates to the level of risk occurring if the equipment fails.

Risk Category III: Preventive Maintenance Requirement (P); this factor reflects the level and frequency of required preventive maintenance.

Risk Category IV: Likelihood of Equipment failure $(\mathrm{F})$; this factor relates to the assumed mean time between failures (MTBF) and failure rate based on equipment service and incident history.

Risk Category V: Environmental use classification (U); which provides the primary use area of equipment.

Each of above risk categories include particular sub-categories with points assigned to them. A total risk score of 3 to 20 is obtained when these points are added together according to the formula: 


$$
\text { Total risks core }=E+A+\left[\frac{P+F+U}{3}\right]
$$

Based upon the total risk score the equipment is evaluated for inclusion into the MEMP.

The risk criteria categories above show that ASHE risk evaluation is a sophisticated level of failure mode and effects analysis (FMEA).

APPENDIX A contains risk criteria category description and the calculated ASHE scores for the medical equipment in this study.

\subsection{Types of maintenance at KHCC}

KHCC conducts both preventive and corrective maintenance to its medical equipment according to four maintenance schemes:

In-house maintenance: In this type, maintenance tasks are carried out at the biomedical engineering department (BME) within KHCC by dedicated technical staff. If any replacement parts are needed for any device under maintenance, they would be ordered directly from the manufacturers or their local agents. This type of maintenance is usually used with low price equipment.

In-house-to-company: Maintenance of medical equipment would be carried out by BME at KHCC as a first trial. In case of BME being not able to repair the failed piece of equipment then it will be sent to the manufacturer or their local representative for repair. This type of maintenance is generally used with medium price equipment.

Maintenance contracts: This maintenance scheme is normally applied to hightech and expensive equipment where a formal interactive agreement between KHCC and the manufacturers' local agents is compiled in order to maintain the equipment after warranty expiry. This normally covers all types of maintenance (PM and CM) for a payment amount determined in the contract which is normally valid for a period of one year.

Lease contracts This scheme usually applies to analytical equipment in which case KHCC guarantee to purchase all supplements and consumables of specific equipment from the manufacturer's local agent while, in return, these agents provide maintenance works for free.

\section{Equipment Selection for Present Study}

Three criteria were identified as basis for equipment selection:

- Similar equipment from the same department

- Different equipment from different departments

- Combinations of Similar equipment from different departments.

The third criterion was chosen to pinpoint effects of differences in work conditions on equipment performance, reliability and maintenance cost. 
Furthermore, the total number of equipment selected for study has been specified to be around 20 to 30 devices. This number range is not too large to allow multiple replications so that unnecessary repetition is avoided and not too small for providing meaningful picture of medical equipment at KHCC.

After discussion with BME staff members, at KHCC, about the choice of a representative set of devices with reliable failure and repair data a final set of 21 devices was selected. The final selected set of equipment are listed in Table 1 with some relevant data about function, department, price, installation date and type of maintenance.

\section{$4 \quad$ Reliability Calculation and Reliability Rank}

In this section, reliability calculation, based on historical failure data, and reliability ranking for all the selected equipment are explained.

\subsection{Time to failure (TTF) data}

TTF data for selected equipment are shown in Table 2. For example, ANAU 11 had failed initially after 189 days from installation, the second failure happened after 172 day from maintenance after the first failure, the third failure happened after 18 days of second maintenance and the fourth failure happened 153 days after the third maintenance.

Table 1. List of medical equipment selected for analysis (prices are listed in local Jordanian currency; JD 1= US\$1.4)

\begin{tabular}{|l|l|l|c|c|c|c|}
\hline $\begin{array}{c}\text { Equipment } \\
\text { Code }\end{array}$ & $\begin{array}{l}\text { Equipment } \\
\text { Name }\end{array}$ & Department & $\begin{array}{c}\text { Installation } \\
\text { Date }\end{array}$ & $\begin{array}{c}\text { Price of } \\
\text { Equipment } \\
\text { (JD) }\end{array}$ & $\begin{array}{c}\text { Type of } \\
\text { Maintenance }\end{array}$ & $\begin{array}{c}\text { Total Annual } \\
\text { Maintenance } \\
\text { Cost (JD) }\end{array}$ \\
\hline ANAU 11 & $\begin{array}{l}\text { Anesthesia } \\
\text { Machine }\end{array}$ & Anesthesiology & $3-03-2013$ & $40 \mathrm{~K}$ & In house & 550 \\
\hline ANAU 13 & $\begin{array}{l}\text { Anesthesia } \\
\text { Machine }\end{array}$ & Anesthesiology & $13-03-2013$ & $40 \mathrm{~K}$ & In house & 550 \\
\hline BCCO 12 & $\begin{array}{l}\text { Hematology } \\
\text { analyzer }\end{array}$ & Hematology Lab & $1-02-2010$ & $80 \mathrm{~K}$ & Lease contract & 0 \\
\hline CLAN 04 & $\begin{array}{l}\text { Chemistry } \\
\text { analyzer }\end{array}$ & Chemistry Lab & $13-03-2013$ & $130 \mathrm{~K}$ & Lease contract & 0 \\
\hline COAG 06 & $\begin{array}{l}\text { Coagulation } \\
\text { analyzer }\end{array}$ & $\begin{array}{l}\text { Operating Room } \\
\text { Nursing }\end{array}$ & $02-08-2010$ & $30 \mathrm{~K}$ & In house & 830 \\
\hline $\begin{array}{l}\text { DEFI } \\
19\end{array}$ & $\begin{array}{l}\text { Defibrillator } \\
\text { Deperating Room } \\
\text { Nursing }\end{array}$ & $14-03-2013$ & $12 \mathrm{~K}$ & In house & 290 \\
\hline $\begin{array}{l}\text { DEFI } \\
\text { Defibrillator }\end{array}$ & $\begin{array}{l}\text { Operating Room } \\
\text { Nursing }\end{array}$ & $18-03-2013$ & $12 \mathrm{~K}$ & In house & 290 \\
\hline DGBP 06 & $\begin{array}{l}\text { Digital blood } \\
\text { pressure } \\
\text { gauge }\end{array}$ & $\begin{array}{l}\text { Outpatient BMT } \\
\text { Nursing }\end{array}$ & $18-03-2013$ & 1,250 & In house & 800 \\
\hline DGBP 12 & $\begin{array}{l}\text { Digital blood } \\
\text { gauge }\end{array}$ & $\begin{array}{l}\text { Surgical Ward } \\
\text { Nursing }\end{array}$ & $18-03-2013$ & 1,250 & In house & 800 \\
\hline
\end{tabular}




\begin{tabular}{|c|c|c|c|c|c|c|}
\hline ECGR 28 & $\begin{array}{l}\text { ECGMa- } \\
\text { chine }\end{array}$ & $\begin{array}{l}\text { Surgical Ward } \\
\text { Nursing }\end{array}$ & 05-01-2011 & $30 \mathrm{~K}$ & In house & 540 \\
\hline LINAC 01 & $\begin{array}{l}\text { Digital linear } \\
\text { accelerator }\end{array}$ & $\begin{array}{l}\text { Radiation Oncol- } \\
\text { ogy }\end{array}$ & $17-03-2010$ & $1.6 \mathrm{M}$ & Contracted & 46150 \\
\hline LINAC 02 & \begin{tabular}{|l|}
$\begin{array}{l}\text { Digital linear } \\
\text { accelerator }\end{array}$ \\
\end{tabular} & $\begin{array}{l}\text { Radiation Oncol- } \\
\text { ogy }\end{array}$ & $18-05-2007$ & $1.6 \mathrm{M}$ & Contracted & 104725 \\
\hline LINAC 03 & \begin{tabular}{|l|} 
Digital linear \\
accelerator
\end{tabular} & $\begin{array}{l}\text { Radiation Oncol- } \\
\text { ogy }\end{array}$ & $18-05-2007$ & $1.6 \mathrm{M}$ & Contracted & 104725 \\
\hline LINAC 04 & $\begin{array}{l}\text { Digital linear } \\
\text { accelerator }\end{array}$ & $\begin{array}{l}\text { Radiation Oncol- } \\
\text { ogy }\end{array}$ & $18-07-2010$ & $1.6 \mathrm{M}$ & Contracted & 46150 \\
\hline MAMM 03 & Mammogram & $\begin{array}{l}\text { DiagnosticRadi- } \\
\text { ology }\end{array}$ & $12-03-2008$ & $250 \mathrm{~K}$ & Contracted & 22010 \\
\hline MAMM 08 & Mammogram & $\begin{array}{l}\text { Early Detection } \\
\text { Nursing }\end{array}$ & 06-03-2013 & $250 \mathrm{~K}$ & Contracted & 22010 \\
\hline $\begin{array}{l}\text { MRIS } \\
02 \\
\end{array}$ & MRI unit & $\begin{array}{l}\text { Diagnostic } \\
\text { Radiology }\end{array}$ & $12-03-2006$ & $1.2 \mathrm{M}$ & Contracted & 49700 \\
\hline $\begin{array}{l}\text { MRIS } \\
03\end{array}$ & MRI unit & $\begin{array}{l}\text { Diagnostic } \\
\text { Radiology }\end{array}$ & $08-05-2012$ & $1.2 \mathrm{M}$ & Contracted & 62480 \\
\hline PORM 05 & $\begin{array}{l}\text { Blood gas } \\
\text { analyzer }\end{array}$ & \begin{tabular}{|l|} 
Operating Room \\
Nursing
\end{tabular} & $31-12-2014$ & $20 \mathrm{~K}$ & In house & 800 \\
\hline ULSO 06 & $\begin{array}{l}\text { Ultra sound } \\
\text { machine }\end{array}$ & $\begin{array}{l}\text { Diagnostic } \\
\text { Radiology }\end{array}$ & 29-03-2007 & $70 \mathrm{~K}$ & $\begin{array}{l}\text { In house to } \\
\text { company }\end{array}$ & 5833 \\
\hline ULSO 19 & $\begin{array}{l}\text { Ultra sound } \\
\text { machine }\end{array}$ & $\begin{array}{l}\text { Radiation Oncol- } \\
\text { ogy Nursing }\end{array}$ & 24-11-2012 & $70 \mathrm{~K}$ & $\begin{array}{l}\text { In house to } \\
\text { company }\end{array}$ & 5833 \\
\hline
\end{tabular}

Table 2. Time to failure (TTF) data for selected medical equipment

\begin{tabular}{|c|c|c|c|c|c|c|c|c|c|c|c|c|}
\hline \multirow{2}{*}{\begin{tabular}{|c|}
$\begin{array}{c}\text { Equipment } \\
\text { Code }\end{array}$ \\
ANAU11
\end{tabular}} & \multicolumn{12}{|c|}{ TTF (DAYS) } \\
\hline & 189 & 172 & 18 & 153 & & & & & & & & \\
\hline ANAU13 & 271 & 189 & 210 & 18 & 177 & & & & & & & \\
\hline BCCO12 & 131 & 24 & 28 & 37 & 177 & 8 & & & & & & \\
\hline CLAN4 & 50 & 85 & 116 & 475 & & & & & & & & \\
\hline COAG06 & 42 & 53 & 40 & 62 & 29 & 161 & 82 & 10 & 3 & & & \\
\hline DEFI19 & 38 & 81 & 1 & 30 & 41 & 7 & & & & & & \\
\hline DEFI 22 & 38 & 40 & 1 & 30 & 59 & 31 & 7 & & & & & \\
\hline DGPBP 06 & 150 & 180 & 610 & 34 & 130 & 206 & & & & & & \\
\hline DGBP12 & 60 & 95 & 98 & 548 & 65 & & & & & & & \\
\hline ECGR28 & 136 & 14 & 23 & 9 & & & & & & & & \\
\hline \multirow{2}{*}{ LINAC 01} & 1 & 10 & 12 & 72 & 19 & 9 & 80 & 7 & 10 & 13 & 14 & 36 \\
\hline & 31 & 13 & 16 & 32 & 31 & 14 & 17 & 34 & 37 & & & \\
\hline \multirow{2}{*}{ LINAC 02} & 28 & 88 & 18 & 15 & 3 & 4 & 2 & 1 & 21 & 23 & 18 & 4 \\
\hline & 1 & 41 & 4 & 10 & 141 & 48 & 2 & 27 & 35 & 1 & 57 & 10 \\
\hline \multirow{3}{*}{ LINAC 03} & 9 & 3 & 1 & 1 & 70 & 2 & 6 & 6 & 50 & 3 & 10 & 27 \\
\hline & 9 & 57 & 3 & 5 & 13 & 5 & 8 & 67 & 14 & 2 & 10 & 51 \\
\hline & 33 & 54 & & & & & & & & & & \\
\hline \multirow{3}{*}{ LINAC 04} & 20 & 6 & 8 & 27 & 9 & 2 & 10 & 2 & 14 & 4 & 3 & 6 \\
\hline & 2 & 1 & 4 & 2 & 7 & 14 & 8 & 6 & 20 & 10 & 5 & 15 \\
\hline & 1 & 20 & 8 & 1 & 11 & & & & & & & \\
\hline MAMM 03 & 7 & 4 & 14 & 26 & 45 & 2 & 4 & 46 & 10 & 43 & & \\
\hline MAMM 06 & 548 & 240 & 69 & 34 & 13 & 58 & 6 & 69 & 131 & 332 & & \\
\hline
\end{tabular}




\begin{tabular}{|c|c|c|c|c|c|c|c|c|c|c|c|c|}
\hline MAMMO 8 & 44 & 324 & 67 & 60 & 578 & 148 & 247 & & & & & \\
\hline \multirow[t]{2}{*}{ MRIS 02} & 40 & 30 & 2 & 47 & 10 & 1 & 46 & 96 & 4 & 77 & 5 & 5 \\
\hline & 46 & 9 & 4 & 3 & 6 & 13 & 8 & 25 & & & & \\
\hline \multirow{2}{*}{ MRIS 03} & 17 & 4 & 14 & 25 & 30 & 8 & 7 & 2 & 16 & 1 & 3 & 45 \\
\hline & 20 & 1 & 14 & 10 & 12 & 12 & 20 & 10 & 1 & 5 & & \\
\hline PORM 05 & 163 & 50 & 302 & 291 & 7 & & & & & & & \\
\hline \multirow{2}{*}{ ULSO 06} & 187 & 5 & 150 & 11 & 31 & 6 & 27 & 17 & 18 & 76 & 54 & 49 \\
\hline & 4 & 11 & 150 & 13 & 5 & 40 & 123 & & & & & \\
\hline ULSO 19 & 510 & 317 & 45 & 8 & 7 & & & & & & & \\
\hline
\end{tabular}

\subsection{Identification of failure density function and probability distribution}

To determine the failure density functions and probability distributions, the TTF data were analyzed using the Minitab ${ }^{\circledR}$ software using histogram and probability plots as shown in Figures 1 and 2.

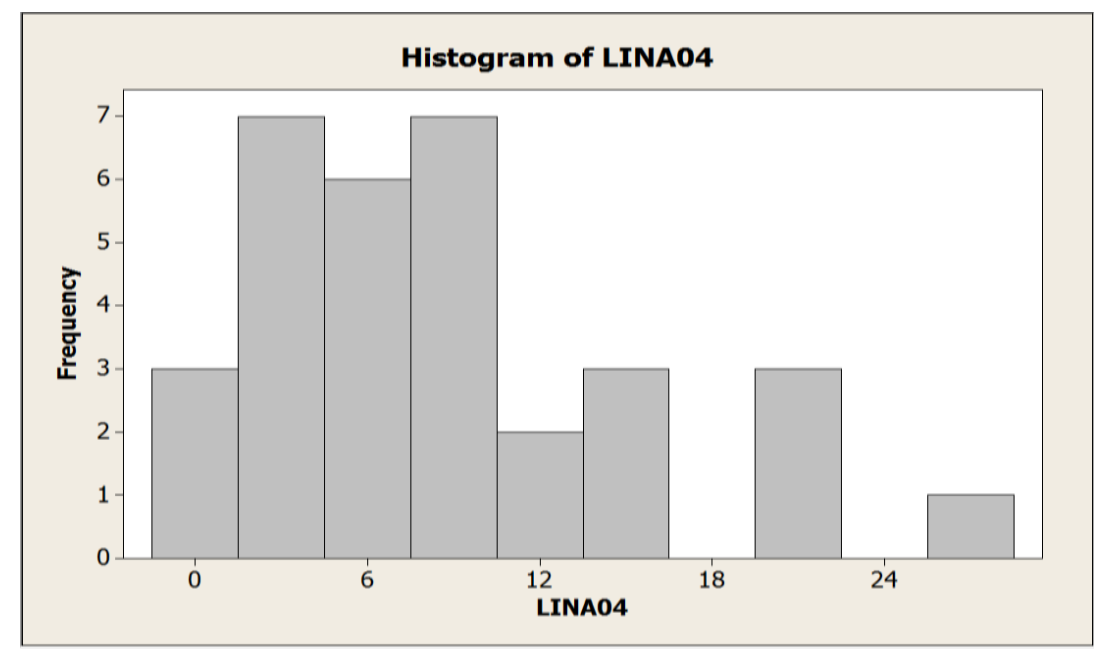

Fig. 1. Histogram for the LINAC-04 device

Selection of the most suitable distribution from the results is carried out depending on the p-value and Anderson test (AD), as shown in Figure 3. Distributions were selected with maximum p-value and minimum AD. 


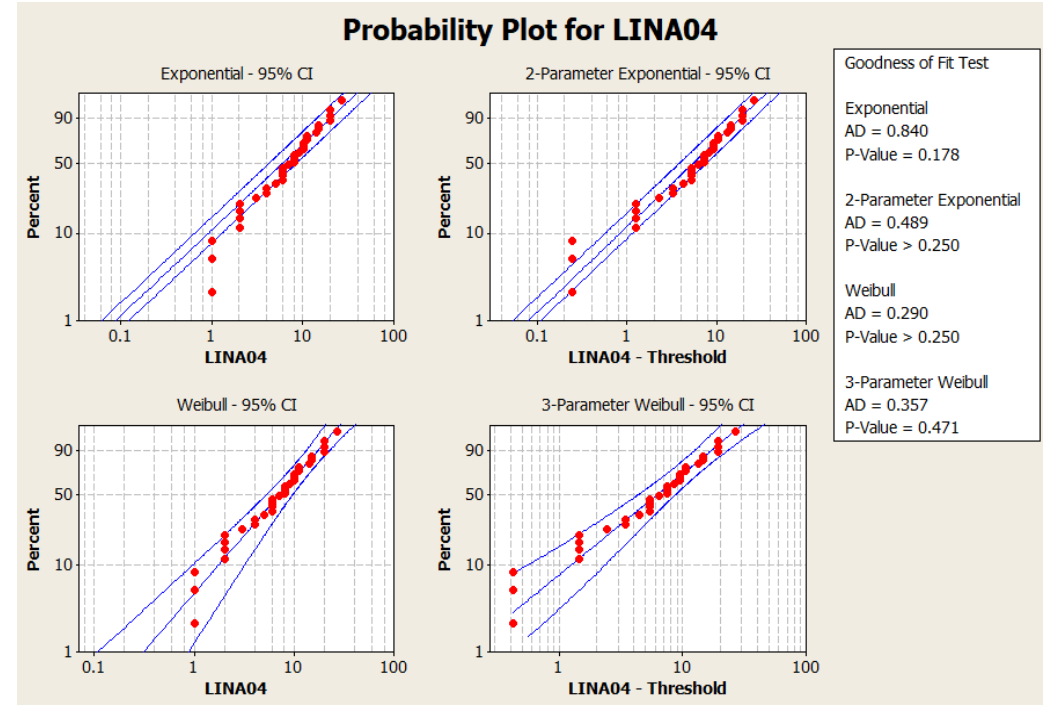

Fig. 2. Minitab® probability plots for LINAC 04

From Figures 2 and 3, the distribution for LINAC-04 is a 3-parameter Weibull distribution shape, scale and threshold values of $1.176,8.42$ and 0.5817 , respectively.

\begin{tabular}{|c|c|c|c|c|}
\hline Distribution & Location & Shape & Scale & Threshold \\
\hline Normal* & 8.56250 & & 6.53002 & \\
\hline Box-Cox Transformation* & 2.71169 & & 1.11724 & \\
\hline Lognormal* & 1.80761 & & 0.92030 & \\
\hline 3-Parameter Lognormal & 2.04258 & & 0.70976 & -1.15569 \\
\hline Exponential & & & 8.56250 & \\
\hline 2-Parameter Exponential & & & 7.80644 & 0.75605 \\
\hline Weibull & & 1.34451 & 9.34351 & \\
\hline 3-Parameter Weibull & & 1.17622 & 8.42127 & 0.58172 \\
\hline Smallest Extreme Value & 12.04987 & & 7.54305 & \\
\hline Largest Extreme Value & 5.68964 & & 4.69170 & \\
\hline Gamma & & 1.61809 & 5.29173 & \\
\hline 3-Parameter Gamma & & 1.27096 & 6.31519 & 0.53613 \\
\hline Logistic & 7.82428 & & 3.55800 & \\
\hline Loglogistic & 1.87839 & & 0.52517 & \\
\hline 3-Parameter Loglogistic & 1.95934 & & 0.47579 & -0.44323 \\
\hline Johnson Transformation* & 0.06665 & & 1.06825 & \\
\hline
\end{tabular}

Fig. 3. Parameters of possible probability distributions using TTF data for LINAC 04

\subsection{Reliability calculation}

Reliability values of equipment were determined using the following formula:

$$
R(t)=1-F(t)=1-\int_{0}^{t} f(t) d t
$$


Where,

$\mathrm{R}(\mathrm{t})$ : reliability function

$\mathrm{F}(\mathrm{t})$ : cumulative probability distribution

$\mathrm{f}(\mathrm{t})$ : failure density function

From the failure density functions determined in section 4.2, the reliability for each equipment was determined by plotting its failure density function distribution and finding the area under the curve, Figure 4.

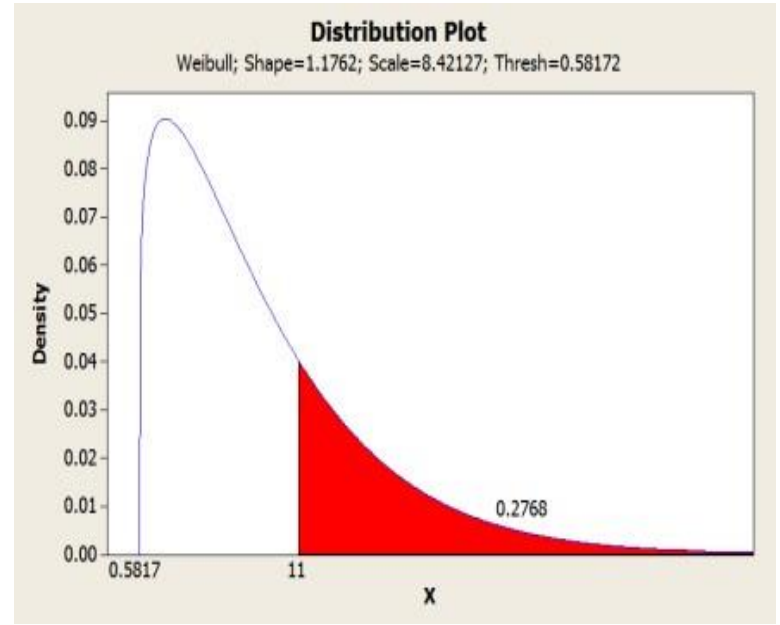

Fig. 4. Probability Plot for LINAC 04

\subsection{Reliability ranking}

After finding reliability for the different equipment, reliability ranks were determined using a standardization method as follows:

$$
\text { standardized reliability rank }=\frac{R-R \min }{R \max -\mathrm{Rmin}}
$$

For example, reliability rank for LINAC 04

standardized reliability rank $=\frac{0.2768-0.2768}{0.9777-0.2768}=0$

Then the reliability rank is determined as follows:

$$
\text { Reliability rank }=10(1-\text { standardizaed reliability rank })
$$

For example reliability rank for LINAC $04=10(1-0)=10$.

The higher the reliability rank the higher the criticality of the equipment. 
Table 3 presents equipment failure density functions, reliability and reliability ranks for all equipment.

Table 3. Failure density functions, reliability and reliability ranks for the selected equipment

\begin{tabular}{|c|c|c|c|c|c|c|}
\hline \multirow{2}{*}{$\begin{array}{c}\text { Equipment } \\
\text { Code }\end{array}$} & \multirow[b]{2}{*}{ Failure Density Function } & \multicolumn{3}{|c|}{ Function parameters } & \multirow[b]{2}{*}{ Reliability } & \multirow{2}{*}{$\begin{array}{l}\text { Reliability } \\
\text { rank }\end{array}$} \\
\hline & & Scale & Shape & Thresh & & \\
\hline ANAU 11 & Exponential & 132.99 & & & 0.9631 & 1 \\
\hline ANAU 13 & Exponential & 173 & & & 0.9715 & 1 \\
\hline BCCO 12 & Exponential & 67.5 & & & 0.8882 & 2 \\
\hline CLAN 04 & Exponential & 181.499 & & & 0.9728 & 1 \\
\hline COAG 06 & Exponential & 53.5556 & & & 0.8612 & 2 \\
\hline $\begin{array}{l}\text { DEFI } \\
19 \\
\end{array}$ & Weibull & 76.668 & 2.81 & 35.098 & 0.8506 & 2 \\
\hline $\begin{array}{l}\text { DEFI } \\
22\end{array}$ & Normal & 29.428 & 18.8902 & & 0.9020 & 2 \\
\hline DGBP 06 & Exponential & 218.33 & & & 0.9774 & 1 \\
\hline DGBP 12 & Exponential & 173.199 & & & 0.9715 & 1 \\
\hline ECGR 28 & Exponential & 45.5 & & & 0.8574 & 2 \\
\hline LINAC 01 & Log logistic & 0.47425 & & & 0.8475 & 2 \\
\hline LINAC 02 & Weibull & 19.228 & 0.6915 & 0.7514 & 0.5235 & 8 \\
\hline LINAC 03 & Lognormal & 1.30794 & & & 0.4595 & 8 \\
\hline LINAC 04 & Weibull & 8.42127 & 1.1762 & 0.58172 & 0.2768 & 10 \\
\hline MAMM 03 & Exponential & 20.1 & & & 0.6080 & 6 \\
\hline MAMM 08 & Exponential & 214.85 & & & 0.9770 & 1 \\
\hline MRIS 02 & Lognormal & 1.2998 & & & 0.4961 & 7 \\
\hline MRIS 03 & Exponential & 12.59 & & & 0.6209 & 6 \\
\hline PORM 05 & Exponential & 162.4 & & & 0.9817 & 1 \\
\hline ULSO 06 & Lognormal & 1.2498 & & & 0.7578 & 4 \\
\hline ULSO 19 & Lognormal & 2.00159 & & & 0.8804 & 2 \\
\hline
\end{tabular}

\section{$5 \quad$ Maintenance Cost Ranking}

Nine cost ranges were determined, for maintenance, by dividing the overall maintenance cost range (highest cost - minimum cost) by 9 (desired number of ranges).

$$
\frac{\not D 104_{725}-j D 0}{9}=J D 12,5
$$

Even though 10 rank values are needed, only 9 cost ranges are used here as the values contain zero cost entries. Based on this cost interval a rank of 1 would be allocated to zero maintenance cost, a rank of 2 would be allocated to maintenance between JD 1 and JD 12,500 and so on as given in Table 4. 
Table 4. Maintenance cost ranking

\begin{tabular}{|c|c|}
\hline Cost range (JD) & Rank \\
\hline 0 & 1 \\
\hline $1-12500$ & 2 \\
\hline $12500-25000$ & 3 \\
\hline $25000-37500$ & 4 \\
\hline $37500-50000$ & 5 \\
\hline $50000-62500$ & 6 \\
\hline $62500-75000$ & 7 \\
\hline $75000-87500$ & 8 \\
\hline $87500-100000$ & 9 \\
\hline $100000-112500$ & 10 \\
\hline
\end{tabular}

\section{Equipment Purchase Price Ranking}

The purchase price ranks were determined in the same way as the maintenance cost ranks but ten ranges for equipment overall prices were determined as there is no zero price entries in this case. This was done by dividing the highest equipment cost by 10 (desired number of ranges):

$$
1,600,000 \frac{\not D}{10}=160,000
$$

The ranks for the different price ranges are shows in Table 5.

Table 5. Purchase price ranking

\begin{tabular}{|c|c|}
\hline Cost range (JD) & Rank \\
\hline $1-160,000$ & 1 \\
\hline $160,000-320,00$ & 2 \\
\hline $320,000-480,000$ & 3 \\
\hline $480,000-640,000$ & 4 \\
\hline $640,000-800,000$ & 5 \\
\hline $800,000-960,000$ & 6 \\
\hline $960,000-1,120,000$ & 7 \\
\hline $1,120,000-1,280,000$ & 8 \\
\hline $1,280,000-1,440,000$ & 9 \\
\hline $1,440,000-1,600,000$ & 10 \\
\hline
\end{tabular}

\section{$7 \quad$ Risk Score Ranking}

Equipment in KHCC is classified depending on ASHE risk score as defined in section 2.1.

$$
\text { ASHE risk score }=\mathrm{E}+\mathrm{A}+((\mathrm{P}+\mathrm{F}+\mathrm{U}) / 3)
$$


For example:

ASHE RISK SCORE for ANAU $-11=10+5+(5+3+5) / 3)=$ 19

Appendix A in section 15 contains full details on ASHE risk score calculations for all equipment.

In order to find ranks for risk score, a standardization method is used as follows:

Standardized risks score rank $=\frac{\text { risk score-min riskscore }}{\text { max riskscore-min riskscore }}$

For example:

Standdized rank of risk scoreforCLAN $04=\frac{14-11}{19-11}=0.375$

In order to obtain the rank in the desired format, i.e., integer numbers between 1 and 10 , the standardized rank is multiplied by 10 and rounded up. For example the final risk score rank for CLAN-04 would be 4 .

ASHE risk scores together with risk score ranks for the different equipment are shown in Table 6.

\section{Overall Criticality of Equipment}

The last step is to calculate the overall criticality number for each equipment using the following equation:

For example:

Overall criticality number $=$ maintenance cost rank $\times$ risk score rank $\times$ reliability rank $\times$ purchase price rank

criticality numberfor LINAC $04=10 \times 8 \times 8 \times 10=6400$ 
Table 6. ASHE risk scores and risk score ranks for the selected equipment

\begin{tabular}{|l|c|c|l|c|c|}
\hline $\begin{array}{c}\text { Equipment } \\
\text { Code }\end{array}$ & ASHE Risk Score & $\begin{array}{c}\text { Rank of } \\
\text { Risk Score }\end{array}$ & Equipment Code & $\begin{array}{c}\text { ASHE } \\
\text { Risk Score }\end{array}$ & $\begin{array}{c}\text { Rank of } \\
\text { Risk Score }\end{array}$ \\
\hline ANAU 11 & 19 & 10 & LINAC 01 & 17 & 8 \\
\hline ANAU 13 & 19 & 10 & LINAC 02 & 17 & 8 \\
\hline BCCO 12 & 11 & 1 & LINAC 03 & 17 & 8 \\
\hline CLAN 04 & 14 & 4 & LINAC 04 & 17 & 8 \\
\hline COAG 06 & 11 & 1 & MAMM03 & 13 & 3 \\
\hline DEFI 19 & 18 & 9 & MAMM08 & 13 & 3 \\
\hline DEFI 22 & 18 & 9 & MRIS 02 & 13 & 3 \\
\hline DGBP 06 & 12 & 2 & MRIS 03 & 13 & 3 \\
\hline DGBP 12 & 12 & 2 & PORM 05 & 12 & 2 \\
\hline ECGR 28 & 14 & 4 & ULSO 06 & 11 & 1 \\
\hline & & ULSO 19 & 11 & 1 \\
\hline
\end{tabular}

\section{Discussion and Analysis of Results}

From Table 3, it can be seen that reliability values fall between $27 \%$ and $97 \%$. While this reveals serious differences in performance of maintenance efforts for the different devices, at the same time it poses a concern about planning future maintenance strategies for medical devices at KHCC.

For ease of reference, individual rank values as well as overall criticality numbers of the different equipment are shown in Table 7. Color-coding was used to indicate criticality level for individual ranks and the overall criticality as follows:

For individual rank values:

- Values between 1 to 4: low level criticality; highlighted in blue

- Values between 5 to 6: medium level criticality; highlighted in yellow

- Values between 7 to 10: high level criticality; highlighted in red

For overall criticality values:

- Values between 1 to 100: low level criticality (category "C"); highlighted in blue

- Values between 101 to 1000: medium level criticality (category "B"); highlighted in yellow

- Values between 7 to 10: high level criticality (category "A"); highlighted in red

Level A represents the most critical equipment that contains the following devices: LINAC-02, LINAC-03 and LINAC-04.

It is obvious from Table 6 that the high criticality of these equipment come from the high maintenance cost, high risk score, high initial cost and, surprisingly, the low reliability.

LINAC equipment are identical, but the differences do exist between maintenance contract values due to difference in the age of equipment where older devices (LINAC-02 and LINAC-03) have contract values of JD 104725 each while newer devices (LINAC-01 and LINAC-04) have lower contract value of JD 46150 each. 
Despite the higher contract value, three of the LINAC devices occupy the highest criticality ranks and exhibit major reliability concerns with LINAC-04 scoring the lowest reliability in all equipment $(27.68 \%)$ leading to a criticality level A.

This high criticality of the most expensive set of devices, and especially, with the presence of major reliability concerns indicates that major shifts in the maintenance policy are required such as more effective preventive maintenance measures and/or tighter control on maintenance providers should be achieved.

Level B represents the medium critical equipment that contains the following devices: MRIS-03, MRIS-02, LINAC 01, and MAMM-08.

Here, there is a variety in parameters that led to these devices falling within this criticality range.

MRIS-03 has high price (1.2 million JD), medium reliability (0.6209), low risk score (13) and medium maintenance cost (JD 62480). While MRIS-02 has the same high initial price and low risk score, its reliability value of 0.4961 falls at the verge of the low reliability values.

LINAC-01 medium criticality comes from its high price (1.6 million JD) and medium maintenance contract value equal JD 46150 but it seems to have good reliability.

MAMM-03 exhibits low to medium reliability value of 0.6080 with the rest of other parameters being within acceptable ranges.

Devices falling in this category seem to have low reliability values with respect to their initial prices and maintenance costs which also demands for some changes in their maintenance policy including some more efficient preventive maintenance measures and better control over maintenance providers.

Level C represents the lowest criticality equipment ranging between 1 and 100; which contains the rest of equipment. This low criticality comes from low initial prices, relative maintenance cost, risk scores, overall prices, and high reliability of these equipment.

There is some equipment with low criticality in spite of their high risk score such as DEFI 19, DEFI 22, ANUA 11, and ANUA 13. This indicates to be within important equipment but does not demand any major steps in terms of maintenance strategies of these devices. This also applies to all equipment within level-C criticality category.

Table 7. Color coding and A-B-C analysis of equipment criticality

\begin{tabular}{|c|c|c|c|c|c|}
\hline $\begin{array}{c}\text { Maintenance } \\
\text { cost rank }\end{array}$ & Risk score rank & Reliability rank & \begin{tabular}{|c|} 
Purchase price \\
rank
\end{tabular} & $\begin{array}{l}\text { Overall critical- } \\
\text { ity number }\end{array}$ & $\begin{array}{c}\text { Level of critical- } \\
\text { ity }\end{array}$ \\
\hline 10 & 8 & 8 & 10 & 6400 & \multirow{3}{*}{ Level A } \\
\hline 10 & 8 & 8 & 10 & 6400 & \\
\hline 5 & 8 & 10 & 10 & 4000 & \\
\hline 6 & 3 & 6 & 8 & 864 & \multirow{4}{*}{ Level B } \\
\hline 5 & 3 & 7 & 8 & 840 & \\
\hline 5 & 8 & 2 & 10 & 800 & \\
\hline 3 & 3 & 6 & 2 & 108 & \\
\hline 2 & 9 & 2 & 1 & 36 & \multirow{3}{*}{ Level C } \\
\hline 2 & 9 & 2 & 1 & 36 & \\
\hline 2 & 10 & 1 & 1 & 20 & \\
\hline
\end{tabular}




\begin{tabular}{|l|l|l|l|l|}
\hline 2 & 10 & 1 & 1 & 20 \\
\hline 3 & 3 & 1 & 2 & 18 \\
\hline 2 & 4 & 2 & 1 & 16 \\
\hline 2 & 1 & 4 & 1 & 8 \\
\hline 1 & 4 & 1 & 1 & 4 \\
\hline 2 & 1 & 2 & 1 & 4 \\
\hline 2 & 2 & 1 & 1 & 4 \\
\hline 2 & 2 & 1 & 1 & 4 \\
\hline 2 & 2 & 1 & 1 & 4 \\
\hline 2 & 1 & 2 & 1 & 4 \\
\hline 1 & 1 & 2 & 1 & 2 \\
\hline
\end{tabular}

- Red color indicates high criticality

- Yellow color indicates medium criticality

- Blue color indicates low criticality

The data in Table 7 is presented in the form of a bar chart (Pareto chart) in Figure 5 for ease of reference.

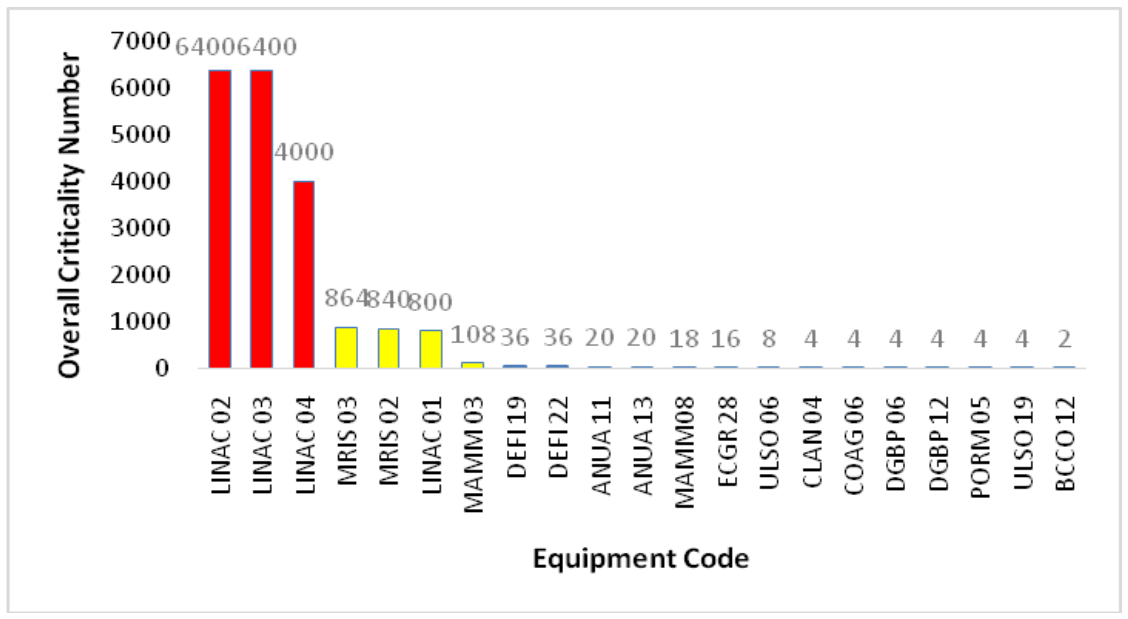

Fig. 5. Pareto chart for overall equipment criticality

\section{Rationale of the Study}

It has been mentioned previously that, at KHCC, criticality of equipment is based solely on the ASHE risk score. The validity of this assumption and its applicability to maintenance prioritization can be checked by comparing the ASHE risk score ranking of the different equipment and their overall criticality obtained from the different ranks. Figure 6 shows the ASHE risk score ranks against overall criticality values. It is obvious, from this Figure 6, that no relationship can be discernable between the ASHE risk score used at KHCC and the calculated criticality of equipment. This implies that the ASHE criticality alone is not adequate to support a decision making 
process for maintenance applications and is only valid for determining "medical criticality". Even though the formula used to calculate the ASHE risk score implicitly contains a component of equipment reliability, by considering preventive maintenance, it is obvious that this implicit incorporation may not be considered as an enough basis for determining medical equipment criticality. The inability for the ASHE risk score to represent actual importance of medical equipment is that the level of preventive maintenance practiced may not be of a "world class" standard [22].

Other issues for explaining this discrepancy between the ASHE risk score and the overall equipment criticality is that the latter takes into consideration other economic and financial factors such as equipment overall price and maintenance cost which are not taken into consideration in calculating the ASHE risk score. These factors are of prime interest to medical institution such as KHCC especially under present financial and economic pressures. This may explain some of the deficiency in the present maintenance strategies applied at KHCC and indicate a need for modifications in these strategies.

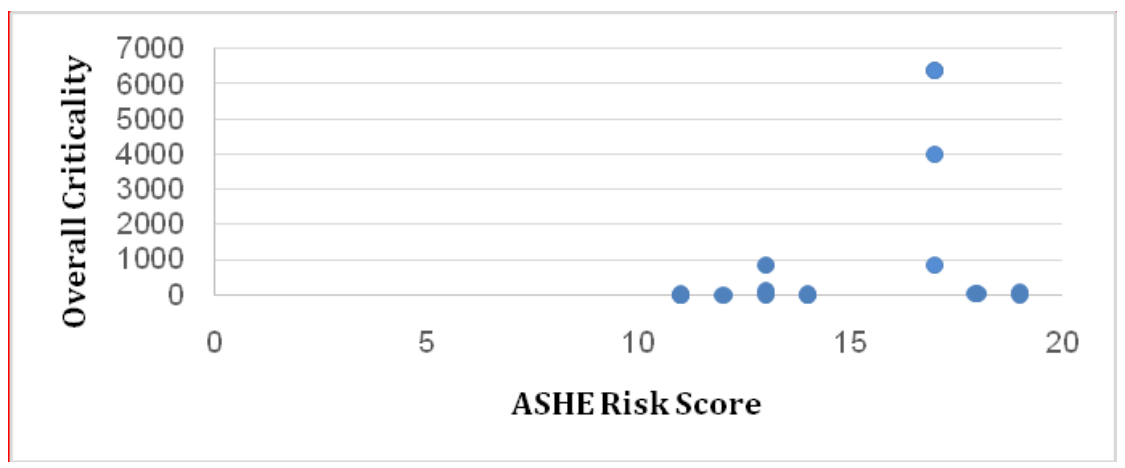

Fig. 6. ASHE risk score ranks vs. overall equipment criticality

\section{Conclusion}

Criticality analysis was carried out on a representative sample of medical equipment at KHCC in Amman-Jordan. Criticality evaluation was based on equipment reliability, ASHE risk scores, and equipment price, and maintenance costs. The present results have revealed that a range of criticality values (in terms of overall criticality ranks) exist between different types of equipment thereby demanding different maintenance management schemes and strategies. The results have also shown that the ASHE risk score alone maybe a misleading measure of medical equipment criticality, especially when it is considered as a basis for maintenance policies. Moreover, it was revealed that major flaws were present in the maintenance management strategies, especially for the highly-expensive equipment, when using the ASHE risk score as the sole measure for medical equipment reliability. 


\section{Acknowledgement}

The authors would like to acknowledge the unique and generous support of KHCC, Amman-Jordan, in particular the Biomedical Engineering Department.

\section{References}

[1] Ascher, H., \& Feingold, H. (1984). Repairable systems reliability: modeling, inference, misconceptions and their causes. ISBN 0-8247-7276-8, CRC Press, Marcel Dekker, Inc., NY.

[2] W. A. Hyman (2003). The theory and practice of preventive maintenance, Journal of Clinical Engineering, Vol. 28, No. 1, pp31-36. https://doi.org/10.1097/00004669-200301000$\underline{00037}$

[3] Atles, L. R. (2008). A practicum for biomedical technology \& management issues. Kendall HuntPublishing, Dubuque, IA.

[4] Wang B, Fennigkoh and Smith, 2006a. Model for inclusion criteria: 15-year retrospective. Interview with Larry Fennigkoh, Journal of Clinical Engineering, Vol. 31, No. 1, pp. 2630. https://doi.org/10.1097/00004669-200601000-00033

[5] Jamshidi A, Rahimi S, Ait-Kadi D, Ruiz A (2014). Medical devices inspection and maintenance: A literature review. Proceedings of Industrial \& Systems Engineering Research Conference, Y. Guan and H. Liao, eds.

[6] Stiefel, R. H. (2009). Medical equipment management manual. 7th ed. AAMI: Annapolis Junction, MD.

[7] Fries, R. C. (2012). Reliable design of medical devices. CRC Press, Taylor and Francis group, NY.

[8] Ridgway, M. G. (2009). Manufacturer-recommendation PM intervals: is it time for a change?. Biomedical Instrumentation \& Technology, Vol. 43, pp. 498-500 https://doi.org/10.2345/0899-8205-43.6.498.

[9] Jardine, A. K., \& Tsang, A. H. (2006). Maintenance, replacement, and reliability theory and applications. CRC Press. https://doi.org/10.1201/9781420044614

[10] Hutagalung, A. O., \& Hasibuan, S. (2019). Determining the priority of medical equipment Maintenance with analytical hierarchy process. iJOE, Vol. 15, No.10, pp. 107-120.

[11] Joint Commission on Accreditation of Healthcare Organizations (JACAHO) (2005). Failure mode and effects analysis in health care: Proactive risk reduction. 2nd ed. Joint Commission on Accreditation: Oakbrook Terrace, IL.

[12] Moubray, J. (1997). Reliability-centered maintenance. Industrial Press Inc.

[13] Dekker, R., Kleijn, M. J., \& De Rooij, P. J. (1998). A spare parts stocking policy based on equipment criticality. International Journal of production economics, Vol. 56, pp. 69-77.

[14] Fennigkoh, L. and Smith, B. (1989). Clinical equipment management. JCAHO Plant Technology and Safety Management Series, Vol. 2, pp. 5-14.

[15] World Health Organization (1998). District health facilities: Guidelines for development \& operations. WHO Regional Publications, Western Pacific Series, No. 22.

[16] World Health Organization (2006). The role of medical devices and equipment in contemporary health care systems and services. WHO, Regional Committee for the Eastern Mediteranean, June 2006. 
[17] Pardeshi, G. S. (2005). Medical equipment in government health facility: Missed opportunities. Indian J Med Sci, Vol.59, No.1, January 2005. https://doi.org/10.4103/0019$\underline{5359.13813}$

[18] Al-Bashir, A., Al-Tawarah, A., and Abdul Jawwad, A. (2017). Downtime reduction on medical equipment maintenance at the directorate of biomedical engineering in the Jordanian MoH. iJOE,Vol. 13, No.2, pp. 4-17. https://doi.org/10.3991/ijoe.v13i02.6422

[19] Miniati, R., Dori, F., Iadanza, E., \& Medici, F. (2008). A new failure analysis for maintenance management in complex hospitals. Proceedings of World Academy of Science, Engineering and Technology, Vol. 34 .

[20] Khalaf, A. (2004). Maintenance model for minimizing risk and optimizing cost effectiveness of medical equipment in Palestine. Journal of Clinical Engineering, December 2004, pp.210-217. https://doi.org/10.1097/00004669-200410000-00048

[21] Bloom, D., Canning, D., Nandakumar, A.K., (2001). Demographic transition and economic opportunity: The case of Jordan. PHR plus, April 2001, TE011.

[22] Zhang, C. and Guo, L. (2013). Fault sampling of complex system under imperfect maintenance. iJOE, Vol. 9, Issue.4, pp. 10-14. https://doi.org/10.3991/ijoe.v9i4.2819

\section{Authors}

Abdul Kareem Abdul Jawwad is an associate professor of Industrial Engineering at King Abdul Aziz University, KSA and The University of Jordan, Amman-Jordan. Dr. Abdul Jawwad is specialized in Failure Analysis, Reliability and Maintenance Engineering in addition to Manufacturing Processes and Manufacturing Systems. Email: akjawwad@ju.edu.jo

Muhammad Saleem is an assistant professor in the department of Industrial Engineering at King Abdul Aziz University, KSA since 2016. He remained as faculty member from 2011 to 2015 at University of Duisburg-Essen, Germany and shared the Chair of Mathematical Engineering at department of Industrial Engineering. His work also focused towards Technical Risk Management, Design of Experiments, and Artificial Intelligence.

Article submitted 2019-09-01. Resubmitted 2019-10-01. Final acceptance 2019-10-05. Final version published as submitted by the authors. 


\section{Appendix A -ASHE Clinical Equipment Risk Evaluation}

\section{Risk criteria category description}

Total risk score $=E+A+\left[\frac{P+F+U}{3}\right]$

Table 8. Risk category I: Equipment function (E)

\begin{tabular}{|c|l|}
\hline Point score & \multicolumn{1}{|c|}{ Function description } \\
\hline 10 & Therapeutic life support \\
\hline 9 & Therapeutic surgical or intensive care \\
\hline 8 & Therapeutic physical therapy or treatment \\
\hline 7 & Diagnostic surgical or intensive care monitoring \\
\hline 6 & Diagnostic other physiological monitoring \\
\hline 5 & Analytical laboratory \\
\hline 4 & Analytical laboratory accessories \\
\hline 3 & Analytical computer and related accessories \\
\hline 2 & Miscellaneous patient related \\
\hline 1 & Miscellaneous non patient related \\
\hline
\end{tabular}

Table 9. Risk category II: Clinical application (A)

\begin{tabular}{|c|l|}
\hline Point score & \multicolumn{1}{|c|}{ Description of use risk } \\
\hline 5 & Potential patient death \\
\hline 4 & Potential patient injury \\
\hline 3 & Inappropriate therapy or Misdiagnosis \\
\hline 2 & Equipment damage \\
\hline 1 & No significant identified risk \\
\hline
\end{tabular}

Table 10.

Risk category III: Preventive maintenance requirement (P)

\begin{tabular}{|c|l|}
\hline Point score & \multicolumn{1}{c|}{ PM frequency } \\
\hline 5 & Monthly \\
\hline 4 & Quarterly \\
\hline 3 & Semi-annually \\
\hline 2 & Annually \\
\hline 1 & Not required \\
\hline
\end{tabular}

Table 11.

Risk category IV: Likelihood of failure (F)

\begin{tabular}{|c|l|}
\hline Point score & \multicolumn{1}{|c|}{ Mean time between failure } \\
\hline 5 & Less than three months \\
\hline 4 & Approximately six months \\
\hline 3 & Approximately one year \\
\hline 2 & Approximately three years \\
\hline 1 & Greater than five year \\
\hline
\end{tabular}


Table 12. Risk category V: Primary area of equipment use (U)

\begin{tabular}{|c|l|}
\hline Point score & \multicolumn{1}{c|}{ Function description } \\
\hline 5 & Anesthetizing locations \\
\hline 4 & Critical care areas \\
\hline 3 & Wet locations/labs/exam areas \\
\hline 2 & General care area \\
\hline 1 & Non-patient area \\
\hline
\end{tabular}

Risk evaluation score analysis

Table 13.

Risk evaluation score analysis

\begin{tabular}{|l|c|c|c|c|c|c|}
\hline \multicolumn{1}{|c|}{ ASHE class } & \multicolumn{4}{c|}{ Risk score } & Total score \\
\hline Analyzer, blood gas $\mathrm{pH}$ & 5 & 3 & 4 & 4 & 3 & 12 \\
\hline Analyzer, coagulation & 5 & 3 & 3 & 3 & 3 & 11 \\
\hline Analyzer, Hematology & 5 & 3 & 3 & 3 & 3 & 11 \\
\hline Analyzer, chemistry & 7 & 4 & 3 & 2 & 4 & 14 \\
\hline Anesthesia & 10 & 5 & 5 & 3 & 5 & 19 \\
\hline Cleaner & 1 & 1 & 2 & 1 & 1 & 3 \\
\hline Defibrillator & 10 & 5 & 4 & 1 & 4 & 18 \\
\hline ECG & 7 & 4 & 3 & 1 & 5 & 14 \\
\hline Ultrasound & 6 & 3 & 3 & 2 & 2 & 11 \\
\hline MRI & 6 & 4 & 3 & 4 & 3 & 13 \\
\hline Digital Blood pressure & 7 & 3 & 2 & 1 & 2 & 12 \\
\hline Linear accelerator & 8 & 5 & 4 & 3 & 4 & 17 \\
\hline Mammography & 6 & 4 & 3 & 4 & 3 & 13 \\
\hline
\end{tabular}

